\title{
Moderne psykologisk behandling ved bipolare lidelser
}

\author{
Ved Gunnar Morken
}

\begin{abstract}
Hensikten med denne artikkelen er å gi en orientering om innholdet i moderne psykologisk behandling ved bipolare lidelser og hvilke behandlingsresultater som er blitt publisert. Fire terapiretninger har utviklet behandlingsformer parallelt som er ganske like i tematisk innhold og tilnærming til pasientene: psykoedukasjon i gruppe, interpersonlig og sosial rytme terapi, familiefokusert terapi og kognitiv individual terapi. Psykoedukasjon i gruppe er den behandlingsformen som er best dokumentert, og vi vil derfor vie den størst oppmerksom her.
\end{abstract}

Behandling av bipolar lidelse er et samarbeidsprosjekt mellom behandler og pasient og vil ofte involvere pårørende. Behandlingen vil som regel omfatte en regulering av pasientens livsstil, noe som ikke nødvendigvis vil oppfattes like positivt av alle pasienter. Mange pasienter opplever også at tidlige faser av mani har positive sider, som de synes det er vanskelig å miste. Det er et særlig problem ved psykologisk behandling av bipolar lidelse at mye av behandlingen foregår i perioder der pasientene kjenner seg friske eller tilnærmet friske. Motivasjonen både for å ta medikamenter hver dag og for gjøre et psykologisk arbeid kan naturlig nok falle i slike perioder. En del pasienter må erfare flere episoder med forverring $f \varnothing r$ de blir motivert for vedlikeholdsbehandling og justering av livsstil (Clatworthy et al., 2009).

\section{Diagnostikk}

Ved bipolar lidelse inntrer periodevise endringer i stemningsleiet som går ut over det man regner som normale humørsvingninger. Ved den diagnostiske vurderingen bruker en den enkelte pasientens normaltilstand som utgangspunkt og unders $\varnothing$ ker

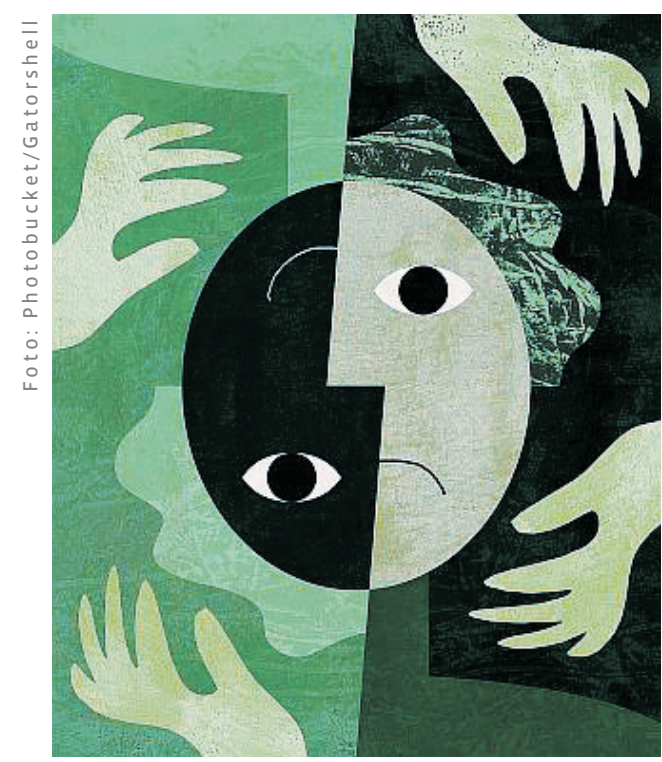

om det har vært depresjoner, blandingstilstander av depresjon og mani, perioder med lett oppstemthet - kalt hypomani eller perioder med alvorlig oppstemthet - kalt mani. Depresjonene skiller seg ikke vesentlig fra depresjoner ved ordinær tilbakevendende depresjon selv om atypiske trekk er noe vanligere. Dersom symptomene i oppstemte episoder er så kraftige at de medfører klar funksjonssvikt, kalles det mani. Det er helt sentralt i diagnostikken å få avdekket hvorvidt symptomene har et episodisk forl $\varnothing p$, dvs. at pasientene har avgrensete perioder med hhv. depresjon, normalt stemningsleie og hypomani/ mani.

Vanligvis deles bipolar lidelse inn i to hovedtyper: bipolar lidelse 1 der pasientene har gjentatte depresjoner og manier, og bipolar lidelse 2 der pasientene har gjentatte depresjoner og hypomanier. Ved bipolar lidelse 2 er således graden av oppstemthet mildere (ICD-10, 1993).

Familiestudier har vist at det er betydelig $\varnothing \mathrm{kt}$ risiko for bipolar lidelse hvis en har en nær slektning med sykdommen. Dette har blitt tolket som at genetiske forhold spiller en stor rolle i utvikling av sykdommen hos den enkelte. Dette sammen med at en tidlig så at psykodynamisk orientert psykologisk behandling syntes å ha begrenset effekt på forløpet, medførte at mange har tenkt at sykdomsforløpet kun kan påvirkes av biologiske behandlingsmåter som medisiner eller ECT (Malt et al., 2006). Utviklingen av moderne psykososial behandling i kombinasjon med en bedre bruk av legemidler synes å være den viktigste nyvinningen i behandling av bipolar lidelse de siste årene.

\section{Farmakologisk behandling}

Farmakologisk behandling virker erfaringsmessig best mot mani der litium, valproat og antipsykotiska er virksomme. Ved forebyggende behandling hvor en bruker litium, lamotrigin, valproat og moderne antipsykotiska, er resultatene noe svakere. Den store utfordringen er behandling av depresjoner der lamotrigin, de moderne antipsykotika quetiapine og olanzapine og sannsynligvis litium og valproat har effekt. Det er diskutert hvilken effekt antidepressiva har ved depresjon hos mennesker med bipolar lidelse (Goodwin et al., 2009).

\section{Psykologisk behandling}

Fire terapiretninger har utviklet behandlingsformer parallelt som er ganske like i tematisk innhold og tilnærming til pasientene. Internasjonalt er det et samarbeid mellom behandlere fra ulike psykoterapitradisjoner som arbeider med bipolar lidelse (Miklowitz, 2008a). Disse terapiretningene er interpersonlig og sosial rytmeterapi ved Ellen Frank i Pittsburgh (Frank et al., 2005a), familiefokusert behandling ved David J. Miklowitz i Denver (Miklowitz et al., 2003), kognitiv atferdsterapi ved Jan Scott (Scott et al., 2006) og Dominic H. Lam (Lam et al., 2005) og psykoedukasjon $i$ gruppe ved Allison Perry i Manchester (Perry et al., 1999) og Francesco Colom i Barcelona (Colom et al., 2009).

\section{Psykoedukasjon i gruppe}

Den terapiretningen som har best dokumentasjon og som vi skal vie størst oppmerksomhet her, er psykoedukasjon i gruppe. Behandlingen er primært utviklet av psykologen Colom og psykiateren Vieta i Barcelona (Colom \& Vieta, 2006). Denne terapiretningen er alene om å kunne legge frem oppfølgingsdata fem år etter en randomisert kontrollert studie, og disse dataene viser at pasientene hadde betydelig færre dager med depresjon eller mani i løpet av fem år enn pasientene i kontrollgruppen som hadde fått annen gruppebehandling (Colom et al., 2009). Behandlingen gis over 20 ukentlige gruppemøter med 8-12 deltakere i gruppene. 
Gruppelederne bør ha erfaring med behandling av bipolar lidelse. Møtene har en fast dagsorden slik vi kjenner det fra kognitiv individualterapi. Hvert gruppemøte består av 30-40 minutter innledning om dagens tema. Deretter følger en $\varnothing$ velse i tilknytning til innledningen som f.eks. å tegne et livsløpskart eller skrive ned en liste med potensielt sykdomsutløsende faktorer, og til sist en gruppediskusjon. Pasientene blir oppmuntret og stimulert til aktiv deltakelse. De făr informasjon om mulige årsaker til lidelsen, symptomutforming, hva som kan virke inn på lidelsen, behandling og hva de selv kan gjøre. Det legges inn hjemmelekser mellom møtene, primært knyttet til registrering av egne symptomer ved hjelp av en dagbok (Colom \& Vieta, 2006).

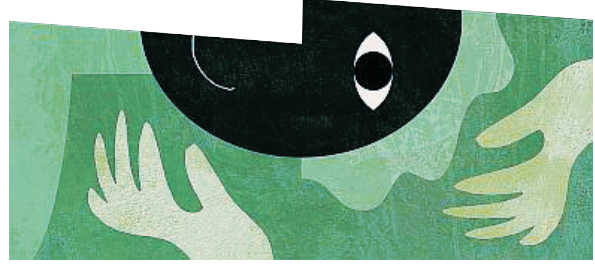

\section{Informasjon om bipolar lidelse}

Deltakerne får informasjon om hva bipolar lidelse er og om behandlingen av sykdommen, inkludert farmakologiske og psykososiale tiltak. Informasjonen knyttes til de enkelte gruppedeltakernes egen erfaring. En søker å $\varnothing$ ke motivasjonen til å ta imot langvarig behandling og selv ta mest mulig kontroll over sykdomsforl $\varnothing \mathrm{p}$ og behandling.

\section{Samarbeid om behandlingen}

Deltakerne tar opp vanskene de har med å følge planlagt behandling, og gruppen går i fellesskap gjennom hva som skjer ved avbrudd av behandling. Videre går en gjennom argumenter for å slutte å ta medikamentene som f.eks. at bivirkninger vil avta hurtig etter at en slutter å ta medisinene, mens det vanligvis tar lengre tid før pasientene får nye sykdomsepisoder pga. mangel på behandling. Informasjon om virkninger og bivirkninger av medikamenter står sentralt. Pasienter kan ha tanker om at det å bruke medikamenter bare er et uttrykk for det å være hjelpeløs og ikke klare å mestre livet selv. Ambivalens i forhold til bruk av medikamenter er således et viktig tema.

\section{Redusere bruk av rusmidler}

I alle beskrivende studier av mennesker med bipolar lidelse er det en betydelig andel av pasientene som har problemer med misbruk av alkohol og andre rusmidler. Det er en klinisk erfaring at selv moderat eller gjennomsnittlig bruk av alkohol medfører $\varnothing \mathrm{kt}$ risiko for nye episoder med depresjon eller mani/hypomani og svekker funksjonen over tid. Det brukes en god del tid i kursene til å hjelpe pasientene til å veie for og mot videre bruk av rusmidler. Det er mulig at mye av effekten psykoedukasjon har til å forebygge depresjoner er knyttet til at pasientene bruker mindre rusmidler etter kursene. For pasienter med rusproblemer vil man i tillegg til den ordinære behandlingen prøve mer mestringsorienterte tiltak og se på alternativer til rusbruk i vanskelige situasjoner.

\section{Tilbakefallsforebygging}

Forebygging av nye episoder med depresjon eller mani/hypomani har flere elementer. A hjelpe pasienten til tidlig å oppdage de første tegnene på mani eller depresjon og planlegge hurtige tiltak for å avverge eller dempe episoden som er på veg, er svært effektivt for å hindre tilbakefall. Pasient og behandler går gjennom tidligere episoder med depresjon, hypomani eller mani og leter etter de første varselsignalene. Tidlige tegn ved perioder med oppstemthet kan variere svært mye fra pasient til pasient. Det kan eksempelvis dreie seg om $\varnothing \mathrm{kt}$ forbruk av kaffe, sigaretter eller alkohol. Eller pasienten selv eller de pårørende kan merke at pasienten er spesielt spøkefull, at han/hun kjører bilen litt fort, bruker mer penger eller liknende.

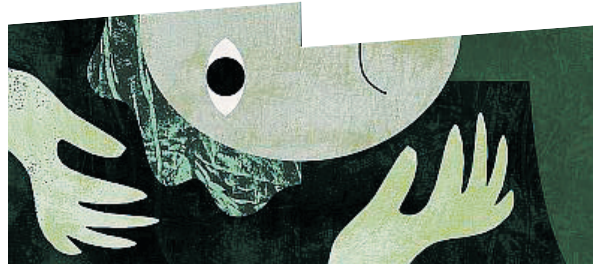

\section{Kriseplan}

Pasient og behandler lager en plan for de tiltakene som antas å være effektive neste gang pasientene får en episode med oppstemthet eller depresjon. Tiltakene vil gjerne involvere pårørende og behandlere i første- og andrelinjetjenesten.
Mange pasienter har ekstra medisiner tilgjengelig hjemme som de kan starte med på egenhånd ved tegn til en ny episode med oppstemthet. I tiltaksplanen kan man legge inn at alle viktige beslutninger skal drøftes med to personer som pasienten stoler på. Planene nedtegnes skriftlig og kan signeres og gis i kopier til de impliserte.

\section{Regulering av daglig aktivitet, livsstil og døgnrytme}

Nesten alle pasienter med stemningslidelser har $\varsigma \varnothing$ vnforstyrrelser i en eller annen form. Pasientene kan sove mer eller mindre enn vanlig og ha urolig $\varsigma \varnothing \mathrm{vn}$. Ved depresjoner føler ofte pasienten $\varnothing \mathrm{kt}$ tretthet som de gjerne oppfatter som mangel på hvile, og som fors $\varnothing$ kes kompensert med mer hvile. Regulering av døgnrytmen synes å ha effekt på forløpet både ved tilbakevendende unipolare depresjoner og ved bipolare depresjoner og oppstemte perioder. I behandlingen vil man være opptatt av å få oversikt over hvilke hendelser som tidligere har medført endring av døgnrytme. En fors $\varnothing$ ker så å hjelpe pasienten til å holde døgnrytmen stabil med samme tid for å våkne og stå opp uavhengig av hvilken sykdomsfase pasienten er i. Regularitet i sosiale rutiner og stabilitet $\mathrm{i}$ interpersonlige forhold har en beskyttende effekt.

\section{Kalender}

Verden over har avdelinger som arbeider med pasienter med bipolar lidelse, tatt i bruk ulike varianter av kalendere der pasientene selv daglig registrerer avvik i stemningsleiet, lengde på s $\varnothing$ vn og grad av angst. Videre registrerer pasientene om det har vært spesielle hendelser eller belastninger, sin bruk av rusmidler og $\mathrm{i}$ hvilken grad de har tatt medikamentene sine. En del pasienter făr en ny innsikt i sammenhengen mellom hendelser og belastninger, symptomer som irritabilitet, søvnvansker og angst og variasjoner i stemningsleiet.

Selv om den bokstavelige forståelsen av begrepet psykoedukasjon kan være opplæring om sykdommen, vil behandlingen ha betydelige elementer som vanligvis forstås som psykoterapi, der pasientene $i$ alle møtene tar opp egne erfaringer og reaksjoner og får respons på disse fra de andre pasientene og gruppelederne. 


\section{Andre psykoterapiformer}

\section{Interpersonlig og sosial rytmeterapi}

Ellen Frank (2005b) har i sin modell for interpersonlig og sosial rytmeterapi videreutviklet tradisjonell interpersonlig terapi ut fra en teori om sosiale tidsgivere ("zeitgebere"), det vil si vaner som bestemmer døgnrytmen. Behandlingen rettes mot forbindelsen mellom affektive symptomer og innholdet $\mathrm{i}$ interpersonlige forhold og i sosiale roller. I behandlingen er man opptatt av å identifisere og håndtere hendelser som kan forstyrre den daglige rytmen. Inspirert av interpersonlig psykoterapi, er man også opptatt av aktuelle forhold til nære personer, som ved ubearbeidet sorg, uenighet med nærstående, endring av roller og mangler i forholdet til andre mennesker. En $\varnothing$ nsker også å redusere risikoen for tilsvarende problemer i fremtiden (Frank, 2005a, 2005b).

\section{Familiefokusert behandling}

David J. Miklowitz og medarbeidere (2003) har utviklet en familietilnærming som har mange likhetstrekk med tilsvarende tiltak for pasienter med schizofreni og deres pårørende. Hensikten er ikke å behandle familien, men å hjelpe familien til å leve best mulig med at et familiemedlem har en langvarig psykisk lidelse som vil kunne veksle mellom depresjonsepisoder, oppstemte perioder i form av hypomani eller mani og gode perioder med normalt stemningsleie. Sentrale elementer er også her psykoedukasjon og tilbakefallsforebygging og å bedre familiens interne kommunikasjon og problemløsning. Et viktig mål er å redusere graden av spenning og frustrasjoner innad i familien. En del symptomer og risikosituasjoner er på et tidlig stadium tydeligere for pår $\varnothing$ rende enn for pasientene. Det å hjelpe pårørende til å bruke sin kunnskap om pasienten til beste for pasienten og familien som helhet blir derfor viktig. Et pragmatisk tilbud til pårørende kan derfor ha stor effekt på forløpet ved bipolar sykdom (Miklowitz, 2008b).

\section{Kognitiv individualterapi}

David Lam m.fl. (2005) og Jan Scott m.fl. (2006) har publisert studier av individualbehandling i form av ukentlige behandlingssesjoner i om lag 20 uker med avtakende hyppighet mot slutten slik at de siste sesjonene fungerer som repetisjon og stimulering ("booster"-sesjoner). Innholdet i timene er tradisjonell kognitiv terapi og det gis hjemmelekser (Lam et al., 1999). Det er vist meget positiv effekt av kognitiv behandling gitt til pasienter med bipolar lidelse. Det gjelder pasienter rekruttert fra spesialiserte poliklinikker og når behandlingen er gitt mens de er i stabilt stemningsleie.

\section{Diskusjon og konklusjon}

Ut over effekten av å oppdage tidlige tegn til mani (Perry et al., 1999), har ingen av de beskrevne behandlingsformene dokumentert effekten av enkeltelementene i behandlingen. Man savner også kunnskap om hvilke undergrupper av pasienter som behandlingsformene virker best overfor. Mye tyder imidlertid på at pasientene bør være i stabilt stemningsleie når de deltar i behandlingen (Scott et al., 2006), og videre at pasientene med de mest alvorlige forl $\varnothing$ pene av bipolar lidelse har behov for en oppfølging som ligner den som gis ved schizofreni i form av psykoseteamene (Bauer et al., 2006). Mennesker med bipolar lidelse som er i stabilt stemningsleie, bør fă tilbud om psykoedukativ gruppebehandling. I Norge er det mulig at dette bør gis fra noen få avdelinger i hver helseregion for å få nok deltakere og jamn drift over tid. Lederne av slike grupper må selv ha betydelig erfaring i å gi behandling til pasienter med bipolar lidelse. Pasienter som av ulike grunner ikke kan delta i grupper, bør få tilpasset individuell psykoedukasjon med de samme elementene som i gruppebehandlingen. Erfaringen fra familiefokusert behandling og interpersonlig terapi taler for at pår $\varnothing$ rende bør få et opplæringstilbud. Mange ganger er det riktig også å ta med familien sammen med pasienten når en arbeider med livsstil, kommunikasjon mellom familiemedlemmer og tiltaksplan ved de første symptomer på en ny episode.

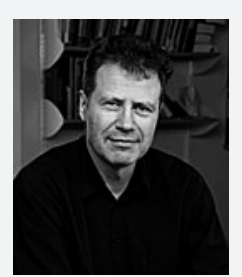

Gunnar Morken er førsteamanuensis ved NTNU og overlege ved avd. $\varnothing_{\text {st }}$ marka, St Olavs Hospital. Han er leder for poliklinikk for bipolare lidelser ved samme sted samt vegleder i kognitiv terapi.

\section{Referanser}

Bauer, M. S., McBride, L., Williford, W. O., Glick, H., Kinosian, B., Beresford, T., Kilbourne, A. M., Sajatovic, M. (2006). Collaborative care for bipolar disorder: Part II. Impact on clinical outcome, function, and costs. Psychiatr.Serv., 57(7), 937-45

Clatworthy, J., Bowskill, R., Parham, R., Scott, J., Horne, R. (2009). Understanding medication nonadherence in bipolar disorders using a NecessityConcerns Framework. J.Affect.Disord., 116(1-2), 51-5.

Colom, F., Vieta, E., Sanchez-Moreno, J., PalominoOtiniano, R., Reinares, M., Goikolea, J. M. et al. (2009). Group psychoeducation for stabilised bipolar disorders: 5-year outcome of a randomised clinical trial. Br.J.Psychiatry, 194, 260-265.

Colom, F., Vieta, E. (2006). Psychoeducation Manual for Bipolar Disorder. London: Cambridge University Press.

Frank, E., Kupfer, D. J., Thase, M. E., Mallinger, A G., Swartz, H. A., Fagiolini, A. M. et al. (2005a). Two-year outcomes for interpersonal and social rhythm therapy in individuals with bipolar I disorder. Arch.Gen.Psychiatry, 62, 996-1004.

Frank, E. (2005b). Treating Bipolar Disorder: A Clinician's Guide to Interpersonal and Social Rhythm Therapy. New York: Guilford Press.

Goodwin, J. M. Consensus Group of the British Association for psychopharmacology. (2009). Evidencebased guidelines for treating bipolar disorder: revised second edition - recommendations from the British Association for Psycho-pharmacology. J

Psychopharmacol., 23(4), 346-88.

ICD-10 Classification of Mental and Behavioural Disorders.(1993). Diagnostic criteria for research. Geneva: World Health Organization.

Lam, D. H., Jones, S. H., Hayward, P., Bright J. A. (1999). Cognitive Therapy for Bipolar Disorder: A Therapist's Guide to Concepts, Methods and Practice. Chichester: John Wiley and Sons.

Lam, D. H., Hayward, P., Watkins, E. R., Wright, K. $\&$ Sham, P. (2005). Relapse prevention in patients with bipolar disorder: cognitive therapy outcome after 2 years. Am.J.Psychiatry, 162, 324-329.

Malt, U. F., Retterst $\varnothing l$, N., Dahl, A. A. (2006). Lærebok i psykiatri. Oslo. Gyldendal.

Miklowitz, D. J. (2008a). Adjunctive psychotherapy for bipolar disorder: state of the evidence. Am.J.Psychiatry, 165, 1408-19.

Miklowitz, D. J. (2008b). Bipolar Disorder: A Familyfocused Treatment Approach. New York: Guilford Publications

Miklowitz, D. J., George, E. L., Richards, J. A., Simoneau, T. L., \& Suddath, R. L. (2003). A randomized study of family-focused psychoeducation and pharmacotherapy in the outpatient management of bipolar disorder. Arch.Gen. Psychiatry, 60, 904-912.

Perry, A., Tarrier, N., Morriss, R., McCarthy, E., \& Limb, K. (1999). Randomised controlled trial of efficacy of teaching patients with bipolar disorder to identify early symptoms of relapse and obtain treatment. BMJ, 318, 149-153.

Scott, J., Paykel, E., Morriss, R., Bentall, R., Kinderman, P., Johnson, T. et al. (2006). Cognitive-behavioural therapy for severe and recurrent bipolar disorders: randomised controlled trial. Br.J.Psychiatry, $188,313-320$ 